\title{
Population Density, Diversity and Abundance of Antelope Species in Kainji Lake National Park, Nigeria
}

\author{
Olajesu Sunday Oladipo, Akinyemi Abiodun Folorunso, Lateef Funmilayo Lewiska, \\ Lameed Gbolagade Akeem \\ Department of Wildlife and Ecotourism Management, Faculty of Agriculture and Forestry, University of Ibadan, \\ Oyo State, Nigeria \\ Email: lateeffunmilayol@gmail.com
}

How to cite this paper: Oladipo, O.S., Folorunso, A.A., Lewiska, L.F. and Akeem, L.G. (2019) Population Density, Diversity and Abundance of Antelope Species in Kainji Lake National Park, Nigeria. Open Journal of Ecology, 9, 107-116.

https://doi.org/10.4236/oje.2019.94009

Received: August 18, 2018

Accepted: April 27, 2019

Published: April 30, 2019

Copyright $\odot 2019$ by author(s) and Scientific Research Publishing Inc. This work is licensed under the Creative Commons Attribution International License (CC BY 4.0).

http://creativecommons.org/licenses/by/4.0/

\begin{abstract}
Habitat degradation and fragmentation are eating deep into conservation areas and this is a serious threat to species diversity and abundance. Species like the antelopes have a sedentary and docile nature which makes them highly vulnerable to habitat degradation or human intrusion. The effect becomes complex as the remaining flora and fauna communities can be significantly impacted by changes in ecosystem structure and function. Population density, diversity and abundance of fauna species will either increase or decrease over time depending on the quality of the environment/habitat and the level of human interference or disturbance. Hence an updated checklist of species diversity and abundance is necessary to enable management and other stakeholders make pragmatic plans and policy towards sustainable species conservation. With the aid of a Global Positioning System (GPS), a $5 \mathrm{~km}$ transect was established per site and censured for Antelope species using the King Census method of enumeration. Descriptive statistics and ANOVA was used to analyze the data. Seven (7) species of Antelopes were recorded. Kobs (Kobus kob) were the most abundant (2019), while Reedbuck (Redunca redunca) was the least abundant with twenty-five (25) individuals. Kob is the most observed species in Oli Complex with $24.13 \%$, ranking about $50 \%$ of kob in proportion. This was followed by roan antelope (Hippotragus equinus), and Red Flanked duiker, $4.02 \%$ and $3.63 \%$ respectively. Kobs had the highest density of 40.38 per square $\mathrm{km}$ followed by roan antelope (3.32) and RF duiker (2.36). Relative density followed a similar trend. The least encounter rate was observed in Sylvicapra grimmia (0.02) and increse further to Hippotragus equinus (0.4), Redunca redunca (0.06) and Alcelaphus buselaphus (0.09) respectively. It was low amongst Tragelaphus scriptus (0.2), and
\end{abstract}


moderate, while it was very high amongst the kobs (5.0). The rate of encountering an antelope in the park is very high at a rate of 6.2 animals per kilometer. Species of antelopes are almost not found in other ranges due to anthropogenic activities around the park. These activities are fast entering into the core area of the park. Hence management should take effective measure to curb this fast-rising problem.

\section{Keywords}

Kainji Lake National Park, Antelopes, Density, Diversity, Abundance

\section{Introduction}

The ecosystem is now constantly changing due to population increase. The increase in human population has led to the release of anthropogenic materials that are harmful to the atmosphere. This demeaning act of man is changing the structure and complexity of the ecosystem and as a result, biodiversity is at a loss. Habitat degradation and fragmentation are eating deep into conservation areas and this is a serious threat to species diversity and abundance. Species like the antelopes have a sedentary and docile nature which makes them highly vulnerable to any habitat degradation or human intrusion. Looking at the feeding habit/pattern of antelopes, they are exclusive grazers and habitat fragmentation as a result of human interference does not only alter landscapes by removing existing natural vegetation but also impacts remaining remnants. The effect becomes complex as the remaining flora and fauna communities can be significantly impacted by changes in ecosystem structure and function. According to Terborgh [1], species distribution, their relative abundance, and composition are often influenced and modified in a manner that is rarely seen at the same level of scale during natural events. The population density, diversity and abundance of fauna species will either increase or decrease over time depending on the quality of the environment/habitat and the level of human interference or disturbance. Hence, an updated checklist of species diversity and abundance is necessary to enable management and other stakeholders make pragmatic plans and policy towards sustainable species conservation. Literature is replete with research work on antelope species in Nigeria. Sodeinde [2] carried out a field survey on a single antelope species (Kob) but limited to dry season, while Jayeola et al. [3] administered questionnaires to neighboring villages and park staff on the status of antelope species. The level of threat and report of widespread elimination of antelope species from its common range [3] [4] [5] is, therefore, a serious concern for this study. Hence, the density and diversity of antelope species were carried out in Kainji Lake National Park with the intention of establishing latest and objective information on the current status and encouraging future research in this direction. 


\section{Study Area}

The study was conducted in Kainji Lake National Park (KLNP) under the Borgu sector of the park. The park is located at Latitude $9^{\circ} 50^{\prime} 19^{\prime \prime} \mathrm{N}$ and Longitude $4^{\circ} 34^{\prime} 24$ "E. KLNP is located in the North West central part of Nigeria between Niger and Kwara States. It is a savanna environment with a total area of 5340.82 sq $\mathrm{km}$ [6]. It is made up of two contiguous sectors; the Borgu and Zugurma Sectors. The Borgu sector is currently 3970.02 sq kilometers and it is bordered on the East side by the Kainji Lake and on the West side by the republic of Benin. Zugurma sector on the other hand occupied a relatively smaller area of 1370.8 sq $\mathrm{km}$.

\section{Materials and Methods}

\subsection{Data Collection}

The study was conducted from September 2012 through August 2014 during dry season and wet season for 14 days in each month. Already existing jeep tracks/roads used by the park management was used to study and collect data. Oli Complex within the park (Figure 1 and Figure 2) was stratified into five

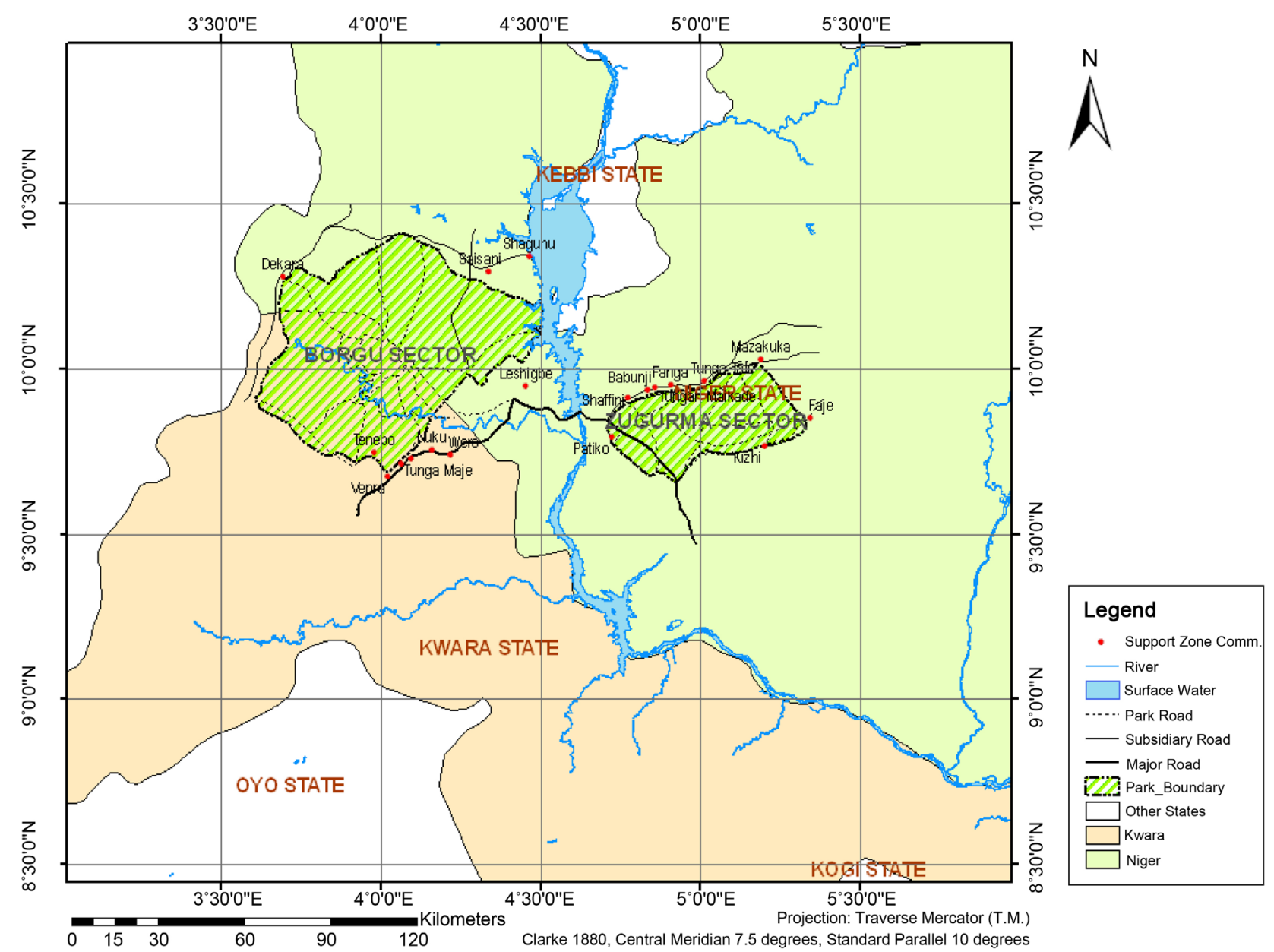

Figure 1. Map of kainji lake national park showing borgu and zugurma sectors. Source: Lameed \& Jenyo-Oni [7]. 


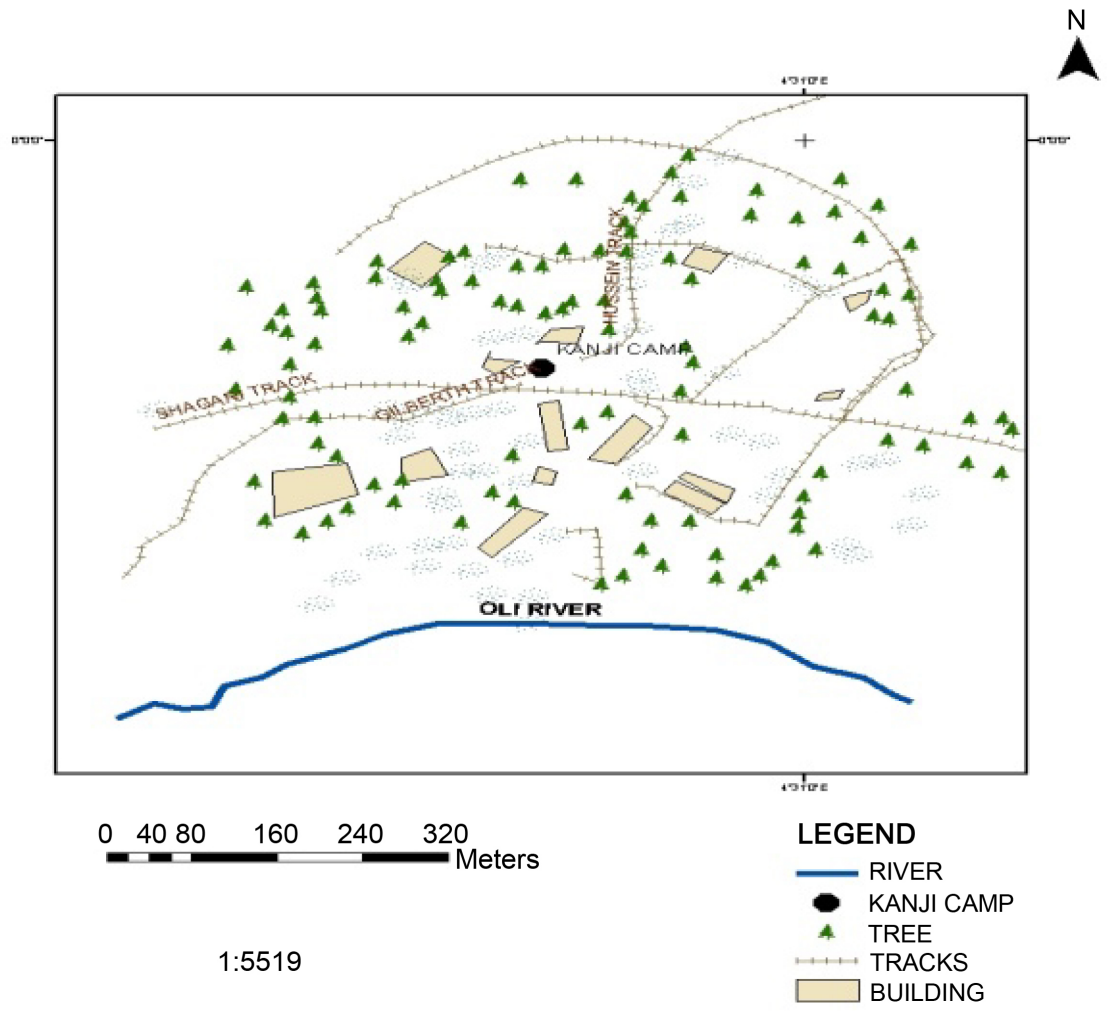

Figure 2. Map showing oli complex within the borgu sector of kainji lake national.

Sites, each within an existing jeep track (based on KLNP master plan, that is, vegetation types and water availability) named, Gilbert Child (GC), Shehu Shagari (SH), Hussein Mashi (HM), Mamudu Lapai (ML), and Mara Tsunade (MT).

With the aid of a Global Positioning System (GPS), a $5 \mathrm{~km}$ transect was established per site and censured for Kob species, morning $(07.00-10.00 \mathrm{~h})$ and evening $(15.00-18.00 \mathrm{~h})$ during each of the dry season and rainy season. King Census method of enumeration was employed for the count. A transect was censured per day. The dry season census was limited to December through March, while the raining season census spanned between June and September. During each count, the site, vegetation type, starting time, weather, date, observer(s) and sheet number were recorded in the animal observation sheet. Transect was walked swiftly at a predetermined speed (approximately $2.0 \mathrm{~km}$ per hour) and counting was carried out on both sides of transect (truncation point of $100 \mathrm{~m}$ perpendicular distance $\{\mathrm{w}\})$. Manual counter and $10 \times 40$ binoculars were used to enhance counting and observation. Whenever a larger herd of animals was encountered, counting was done twice before arriving at a mean value at the sighting point. At the end of census exercise, the transect width was calculated, that is, the mean of the sighting distances for each antelope species.

\subsection{Data Analysis}

Data collected was analyzed to obtain density using the Shannon Weiner's diversity index and species richness was calculated using the formula: 
Relative importance value $($ R.I.V $)=\frac{\text { Relative Density }+ \text { Relative Frequency }}{2}$ where:

Absolute frequency $=$ the chance of occurrence of a species in a quadrat

$$
\text { Relative frequency }=\frac{\text { Frequency of a Spp } \times 100}{\text { Total frequency of all Spp }}
$$

Absolute Density $=$ No of individuals of a Spp per unit area

$$
\text { Relative Density }=\frac{\text { Density of Individuals of Spp } \times 100}{\text { Total density of all Spp }}
$$

\subsection{Encounter Rate}

This was measured as the kilometric Index of Abundance (KI), indicating how easy it is to come across the species in the park. It directly revealed the abundance and distribution of the fauna species in question and can be calculated for all the species available or present in the park. The rate varies, it may be below 0 0.3 , medium/moderate $0.3-0.5$, or it may be higher-greater than 0.5 . The rate was calculated for the antelope species in the complex across strata. This is obtained by dividing the size by the effort. That is,

$$
\text { Encounter rate }=\frac{\text { Population size }}{\text { Kilometric effort }} \text {. }
$$

\section{Results}

Seven (7) species of Antelopes were recorded (Table 1). Kobs (Kobus kob) were the most abundant (2019), while Reedbuck (Redunca redunca) was the least abundant with twenty five (25) individuals. It is significant to note that none of the species were dominant nor were they equally distributed. Even within the same species such as kobs, with high abundance, the equitability was moderate but not equally distributed across the Oli Complex. (Table 2) presents the Relative Importance Value (R.I.V), Density (D), Relative density (R.D), Frequency (F), and Relative Frequency (R.F) of antelopes identified in the study area. Kob is the most observed species in Oli Complex with 24.13\%, ranking about 50\% of kob in proportion. This was followed by roan antelope (Hippotragus equinus), and Red-Flanked Duiker, $4.02 \%$ and 3.63\% respectively. Kobs had the highest density of 40.38 per square $\mathrm{km}$ followed by roan antelope (3.32) and RF duiker (2.36). Relative density followed a similar trend. Status, Number of sighting of observed individual (N) Antelope species in the study area was presented in (Table 3). Seven Antelope species were identified, out of which four were reported endangered, (Hippotragus equinus and Redunca redunca), three were vulnerable, (Kobus kob, Cephalophus rufilatus, and Alcelaphus bucelaphus) while only two species, (Tragelaphus scriptus and Sylvicapra grimmia) were at satisfactory level in Nigeria (Table 3). A total of 614 sightings was recorded for antelopes in the study, $60 \%$ of this was for kob, Red-Flanked Duiker was next (17\%) and Roan antelopes followed (9.78\%). The least was Reedbuck (0.33\%). 
Table 1. Abundance of antelope species in KLNP.

\begin{tabular}{ccc}
\hline SCIENTIFIC NAME & COMMON NAME & ABUNDANCE \\
\hline Kobus kob & Kob & 2019 \\
Hippotragus equinus & Roan Antelope & 166 \\
Cephalophus rufilatus & Red-Flanked Duiker & 118 \\
Tragelaphus scriptus & Bush buck & 76 \\
Alcelaphus buselaphus & Western Hartebeest & 35 \\
Sylvicapra grimmia & Grimms' duiker & 9 \\
Redunca redunca & Reedbuck & 25 \\
\hline
\end{tabular}

Table 2. Relative importance value, density and relative factors of fauna species in oli complex of KLNP.

\begin{tabular}{lccccc}
\hline \multicolumn{1}{c}{ Species } & $\mathrm{RIV}$ & $\mathrm{D}$ & $\mathrm{RD}$ & $\mathrm{F}$ & $\mathrm{RF}$ \\
\hline 1) Kobus kob & 24.13 & 40.38 & 43.27974 & 20 & 4.975124 \\
2) Hippotragus equines & 4.02 & 3.32 & 3.558414 & 18 & 4.477612 \\
3) Cephalophus rufilatus & 3.63 & 2.36 & 2.529475 & 19 & 4.726368 \\
4) Tragelaphus scriptus & 2.93 & 1.52 & 1.629153 & 17 & 4.228856 \\
5) Alcelaphis bucelaplus & 1.37 & 0.7 & 0.750268 & 8 & 1.99005 \\
6) Sylvicapra grimmia & 0.72 & 0.18 & 0.192926 & 5 & 1.243781 \\
7) Redunca redunce & 0.64 & 0.5 & 0.535906 & 3 & 0.746269 \\
\hline
\end{tabular}

KEY: RIV = Relative Importance Values; $\mathrm{RD}=$ Relative Density; RF = Relative Frequency; $\mathrm{D}=$ Density $/ 1000 \mathrm{~km}^{2} ; \mathrm{F}=$ Frequency.

Table 3. The status, number of sightings and observed antelopes in oli complex, KLNP.

\begin{tabular}{|c|c|c|c|}
\hline Species & Status* & Number of Sighting & Size \\
\hline Kobus kob & $\mathrm{V}$ & 371 & 2019 \\
\hline Cephalophus rufilatus & $\mathrm{V}$ & 110 & 118 \\
\hline Tragelaphus scriptus & S & 45 & 76 \\
\hline Hippotragus equinus & En & 60 & 165 \\
\hline Alcelaphus buselaphus & $\mathrm{V}$ & 9 & 35 \\
\hline Redunca redunca & En & 2 & 25 \\
\hline Sylvicapra grimmia & $S$ & 8 & 9 \\
\hline Kobus defassa ${ }^{* *}$ & $\mathrm{~V}$ & 0 & 0 \\
\hline Ourebia ourebi ${ }^{* *}$ & $\mathrm{~V}$ & 0 & 0 \\
\hline
\end{tabular}

En $=$ Endangered; $\mathrm{V}=$ Vulnerable; $\mathrm{S}=$ Satisfactory. ${ }^{* *}=$ present before but not sighted in this study. ${ }^{*}$ East, 1999.

(Table 4) presents the abundance and frequency Distribution of Antelope species across the study sites in Oli Complex. Kob was the most abundant antelope species (2019) and most widely distributed antelope species across the complex. Site GC has the highest kob population size (818), SH is next (634), followed by HM (354) while the smallest kob population was ML (80). Roan antelope was the next (166), followed by RF duiker (118) and Bushbuck (76), the least in abundance 


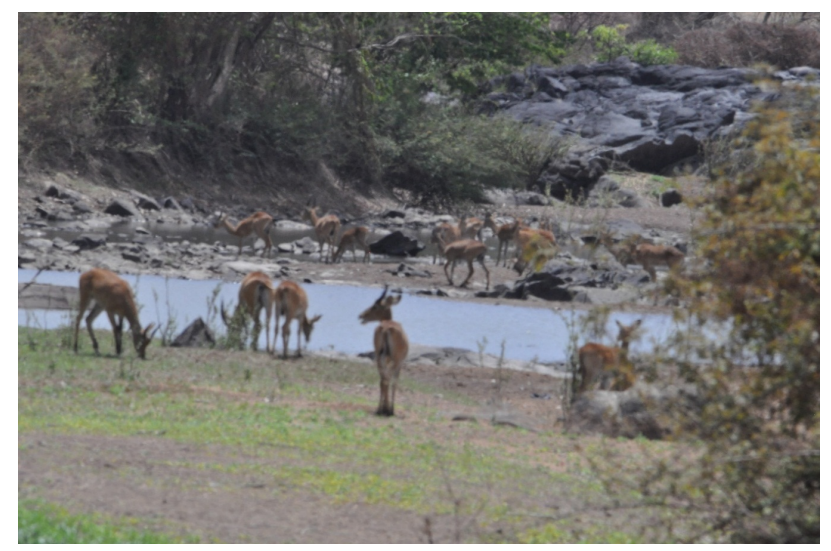

Plate 1. Antelopes drinking at the waterhole in KLNP.

was Reedbuck (25). Site SH had the highest antelope species richness (8), sites GC, ML and HM followed with 7 each, while the least antelope species richness was in site MT (6). GC had the largest average abundance of antelopes (130), followed by SH (89), HM (66) and MT (34). The smallest average (abundance) was observed in ML (27). Among the Antelope species, only four (4) were present in all the strata, that is, Buffon's kob, Red-Flanked Duicker, Roan antelope and bushbuck were widely distributed within the Complex. kobs had a fairly high population in all the strata as compared to the remaining three.

The Encounter Rate of Antelope species in Oli Complex, KLNP was presented in (Table 5). It was very low amongst five species (less than 0.1 ). The least encounter rate was observed in Sylvicapra grimmia (0.02) and increase further toHippotragus equinus (0.4), Redunca redunca (0.06) and Alcelaphus buselaphus (0.09) respectively. It was low amongst Tragelaphus scriptus (0.2), and moderate, while it was very high amongst the kobs (5.0). The rate of encountering an antelope in the park is very high at a rate of 6.2 animals per $\mathrm{km}$. Kob represents $82.0 \%$ of all the antelope species in the park alone, while the remaining $18 \%$ was shared amongst the other antelopes.

\section{Discussions}

Seven antelope species (herbivores) belonging to the family Bovidae were identified. This agrees with IUCN [5] that, 91 out of 97 herbivores identified globally are antelopes. They belong to five subfamilies as outlined by East et al. [8]; Reducinae (Kobus kob and Redunca redunca); Cephalophinae (Cephalophus rufilatus and Silvicapra grimmia); Hippotraginae (Hippotragus equinus); Bovinae (Tragelaphus scriptus); and Alcelaphinae (Alcelaphus bucelaphus). Fifty three percent $(53 \%)$ of the individual animal observed were antelopes. The conservation status of a species is very important as it relates to its continuity or otherwise in the environment. The report of this study revealed that the population size of kob is relatively high but the density is very low; this contradicts the report of Antelope Global Survey (SSC/ASG/IUCN), as compiled by East [4], which label kob has been "Vulnerable" in Nigeria. However, when this is viewed 
Table 4. Abundance and frequency distribution of Antelope species in the study area.

\begin{tabular}{ccccccc}
\hline S/N & SPECIES & $\begin{array}{c}\text { Gilbert } \\
\text { Child (GC) }\end{array}$ & $\begin{array}{c}\text { Shehu } \\
\text { Shagari (SH) }\end{array}$ & $\begin{array}{c}\text { Mamudu } \\
\text { Lapai (ML) }\end{array}$ & $\begin{array}{c}\text { Hussein } \\
\text { Mashi (HM) }\end{array}$ & $\begin{array}{c}\text { Mara Tsude } \\
(\mathrm{MT})\end{array}$ \\
\hline 1 & Kobus kob & 818 & 634 & 80 & 354 & 133 \\
2 & Cephalophus rufilatus & 43 & 30 & 06 & 30 & 09 \\
3 & Hippotragus equinus & 13 & 08 & 74 & 39 & 31 \\
4 & Sylvicapra grimmia & 00 & 01 & 02 & 06 & 00 \\
5 & Tragelaphus scriptus & 23 & 19 & 01 & 19 & 14 \\
6 & Alcelaphus buselaphus & 04 & 08 & 21 & 02 & 00 \\
7 & Redunca redunca & 00 & 00 & 00 & 09 & 16 \\
& Richness & 07 & 08 & 08 & 07 & 06 \\
& Average & 130 & 89 & 27 & 66 & 34 \\
\hline
\end{tabular}

Table 5. Encounter rate of Antelope species in oli complex, KLNP.

\begin{tabular}{cccc}
\hline Species & Size & Effort $(\mathrm{km})$ & E.R $(/ \mathrm{km})$ \\
\hline kobus kob & 2019 & 400 & 5.0475 \\
Cephalophus rufilatus & 118 & 400 & 0.295 \\
Hippopotamus amphibius & 16 & 400 & 0.04 \\
Hippotragus equinus & 165 & 400 & 0.4125 \\
Sylvicapra grimmia & 9 & 400 & 0.0225 \\
Tragelaphus scriptus & 76 & 400 & 0.19 \\
Alcelaphus buselaphus & 35 & 400 & 0.0875 \\
Syncerus caffer & 8 & 400 & 0.02 \\
Redunca redunca & 25 & 400 & 0.0625 \\
Total & 2471 & & 6.1775 \\
\hline
\end{tabular}

E.R $=$ Encounter rate.

on a national and global scale, they may be vulnerable as the species is likely to be very rare elsewhere or outside the proteced area. The total number of sightings for antelopes was 614 of which $60 \%$ was kob, this marked the abundance and relative importance of the species as compared to others in the park. Kobs were observed in clusters of four (4) to nine (9), indicating that they are not solitary animals like the duikers. KLNP was known to be the stronghold for antelopes [4] [9] as such, factors militating against the proliferation of antelopes which includes, habitat destruction, poachers (and or overhunting) and illegal grazing. This is a major challenge to the management of KLNP as antelopes can almost no longer be found in most of the other ranges of the park except Oli Complex. This study agrees with Machlis \& Tichnell [10] and Lameed [11] which emphasized widespread poverty has made rural inhabitants especially adjoining communities to the park to exert pressure on marginal lands for agriculture and or raising livestock.

Migration both seasonal and otherwise has been reported in antelopes, but poaching and livestock grazing (competition with cattle) had greatly diminished 
the range of antelopes in the park as they were no longer found in some of their usual habitat and part of the park. This is in line with Jayeola et al. [3], Poche [12], East [4] and IUCN [5]. Oladipo [13], Anadu and Green [14], Strushsaker and Oates [15] and Onadeko [16]; They highlighted so many factors has been responsible for this ugly development, some of which are, overexploitation of forest, urbanization, resource extraction, mining, construction, farming and a host of others. Illegal hunting and over-exploitation of wildlife most especially herbivorous ungulates like antelopes are badly affected [17] particularly because of their docile nature [14]. Anadu and Green, [14] whose report was limited to Nigeria, also reaffirmed that antelopes have largely been eliminated outside conservation areas. The situation was suspected to be worse today with a lot of advancement in hunting techniques and poaching strategy unfolding daily. The report of this work confirmed this to be worse than it was imagined, as buttressed by Jayeola et al. [3], antelopes are not only eliminated outside the parks but were now restricted mainly to Oli Complex (Oli range) of the park [18], that is, the animal has become rare and vulnerable to extinction in some areas (ranges) even within the park.

\section{Conclusion}

Seven antelope species (herbivores) belonging to the family Bovidae were identified with Kobs having the highest encounter rate, density, and abundance while Reedbuck have the least. The study revealed that antelopes are abundant and have a high density in an undisturbed habitat. Hence, the population density, diversity and abundance of fauna species will either increase or decrease over time depending on the quality of the environment/habitat and the level of human interference or disturbance. Habitat degradation and fragmentation are eating deep into conservation areas and this is a serious threat to species diversity and abundance. Species like the antelopes have a sedentary and docile nature which makes them highly vulnerable to any habitat degradation, hunting, and human intrusion.

\section{Conflicts of Interest}

The authors declare no conflicts of interest regarding the publication of this paper.

\section{References}

[1] Terborgh, J. (2008) Preservation of Natural Diversity: The Problem of Extinction Prone Species. BioScience, 24, 715-722. https://doi.org/10.2307/1297090

[2] Sodeinde, O.A. (1989) Dry Season Habitat Use by Senegal Kob in the Kainji Lake National Park, Nigeria. Mammalia, 53, 353-362. https://doi.org/10.1515/mamm.1989.53.3.353

[3] Jayeola, O.A., Onadeko, S.A, Mafiana, C.F., Inah, E.I. and Okeyoyin, O.A. (2012) Past and Present Status of Kob (Kobus (Adenota) kob (Erxleben) in Nigeria. International Journal of Biodiversity and Conservation, 4, 197-205. 
[4] East, R. (1999) African Antelope Database 1998. IUNC/SSC Antelope Specialist Group Publication, Gland, Switzerland.

[5] IUCN. (2009) IUCN Red List of Threatened Species. Version 2009.1, Gland, Switzerland.

[6] Marguba, L.B. (2002) National Parks and Their Benefits to Local Communities in Nigeria. Nigeria National Park Service, 34, 34-39.

[7] Lameed, G.A. and Jenyo-Oni, A. (2012) Species-Diversity Utilization of Salt Lick Sites at Borgu Sector KLNP, Kainji. In: Lameed, G.A., Ed., Biodiversity Enrichment in a Diverse World, IntechOpen Limited, London, 35-62. https://doi.org/10.5772/3088

[8] East, R., Grubb, P. and Wilson, V.J. (1988) Classification of Antelopes Adopted for the Antelope Survey. In: East, R., Ed., Antelopes. Global Survey and Regional Action Plan, Part 1: East and Northeast Africa, IUNC, Gland, Switzerland and Cambridge UK.

[9] Meduna, A.J., Oyeleke, O.O., Amusa, T.O., Likita, I.B., Ajayi, S.R., Akor, S. and Patrick, V. (2008) Evaluation of Kob (Kobus kob Erxleben) Habitat in KLNP, Nigeria. Obeche Journal, 26, 40-44.

[10] Machlis, G.E. and Tichnell, D.L. (1985) The State of the World's Park. Westview Press, Boulder, CL.

[11] Lameed, G.A. (2007) Kainji Lake National Park of Nigeria: Assets and Implications for Sustainable Development. Biodiversity, 8, 3-13.

https://doi.org/10.1080/14888386.2007.9712831

[12] Poché, R.M. (1976) Seasonal Distribution and Reproduction in Artiodactyla from Southwestern Niger. Niger Fields, XLI, 31-40.

[13] Oladipo, E.O. (2001) International Initiative on Biodiversity Conservation since 1992. In: Poopola, L. and Oluwanna, S.A. Eds., Biodiversity Rainforest Ecosystem in Nigeria. FEPA-UNAAB Linkage Centre for Forest Conservation and Biodiversity. University of Agriculture Abeokuta, Abeokuta, 22-32.

[14] Anadu, P.A. and Green, A.A. (1995) Antelope Survey. Longman Publishers, Harlow, 83-90.

[15] Strushaker, T.T. and Oates, J.F. (1995) The Biodiversity Crisis in Southwestern Ghana. African Primates, 1, 5-6.

[16] Onadeko, S.A. (2004) Home on the Range: Crises; Consequences and Consolations. UNAAB Inaugural Lecture Series, No. 17, 86.

[17] Kingdon, J. (1997) The Kingdom Field Guide to African Mammals. Academic Press, London and New York.

[18] Fischer, F. and Linsenmair, K.E. (2001) Spatial and Temporal Habitat Use of Kob Antelopes (Kobus kob kob, Erxleben 1777) in the Comoé National Park, Ivory Coast as Revealed by Radio Tracking. African Journal of Ecology, 39, 249-256. https://doi.org/10.1046/j.0141-6707.2000.00302.x 